\title{
Du réseau au maillage administratif, la construction territoriale des subdélégations bretonnes de 1689 à 1789
}

An Administrative Network: The Territorial Structures of Breton Subdelegations from 1689 to 1789

Sébastien Didier

\section{OpenEdition}

Journals

Édition électronique

URL : http://journals.openedition.org/abpo/2870

DOI : $10.4000 / a b p o .2870$

ISBN : 978-2-7535-3977-8

ISSN : 2108-6443

Éditeur

Presses universitaires de Rennes

Édition imprimée

Date de publication : 15 décembre 2014

Pagination : 81-106

ISBN : 978-2-7535-3975-4

ISSN : 0399-0826

Référence électronique

Sébastien Didier, « Du réseau au maillage administratif, la construction territoriale des subdélégations bretonnes de 1689 à 1789 », Annales de Bretagne et des Pays de l'Ouest [En ligne], 121-4 | 2014, mis en ligne le 15 décembre 2016, consulté le 23 avril 2019. URL : http://journals.openedition.org/abpo/2870 ; DOI : 10.4000/abpo.2870 


\title{
Du réseau au maillage administratif, la construction territoriale des subdélégations bretonnes de 1689 à 1789
}

\author{
Sébastien DiDIER \\ Professeur d'histoire-géographie au collège de Bergues (59)
}

L'historiographie de l'intendance s'intéresse de plus en plus aux subdélégués depuis les travaux de J. Ricommard et H. Fréville ${ }^{1}$. Cependant, la dimension spatiale de l'intendance et son découpage en subdélégations ne sont souvent abordés qu'à partir de la situation des années 1780. Très utile, le travail cartographique dirigé par Guy Arbellot et Jean-Pierre Goubert doit pourtant être dépassé ${ }^{2}$. Une carte ne suffit pas à rendre les évolutions territoriales et encore moins le processus de construction du territoire administratif dont découle l'organisation de l'ensemble de l'intendance ${ }^{3}$.

Appelées " subdélégations ", " départements " ou encore " cantons " par les sources, les circonscriptions des subdélégués de l'intendance bretonne forment un maillage territorial inventé de toutes pièces. L'intendant commissionne ses subdélégués pour l'informer et exécuter ses ordres d'un bout à l'autre de la province. Leur répartition n'est pas anodine : elle donne lieu à la création d'un nouvel échelon administratif. La subdélégation s'entend donc sous trois sens différents : action de confier son autorité pour être

1. FréVILLE, Henri, L’intendance de Bretagne (1689-1791), Rennes, Plihon, 1953 (3 vol.). RICOMMARD, Julien, "Les subdélégués des intendants aux XVII ${ }^{\mathrm{e}}$ et XVIII ${ }^{\mathrm{e}}$ siècles ", Information historique, 1962, p. 139-148, 190-195 et 1963, p 1-7; id., "L'érection en titre d'office des subdélégués des intendants. L'application dans l'ensemble du royaume de l'édit d'avril 1704 et l'érection en titre d'office des subdélégués des intendants ", Revue Historique, 1945-1, p. 24-25 et 1945-2, p. 123-130, etc.

2. Arbellot, Guy, Goubert, Jean-Pierre, Mallet, Jacques, Palazot, Yvette (dir.), Carte des généralités, subdélégations et élections en France à la veille de la Révolution de 1789, Paris, CNRS, 1986.

3. La présente contribution reprend des idées développées dans DiDIER, Sébastien, Les subdélégués des intendances de Bretagne et de Nouvelle-France, Antrain, Fougères, Hédé et Montréal, une étude prosopographique comparée, mémoire de master sous la direction de Yann LAGADEC, université de Rennes 2, 2011. 
représenté, elle désigne aussi, lorsqu'elle devient permanente, une fonction administrative; par métonymie, le même mot évoque la circonscription territoriale associée à la charge.

La géographie des subdélégations bretonnes interroge les historiens depuis le début. Son originalité interpelle : aucune autre province ne connaît autant de subdélégations et seules celles du Nord et de Provence en comprennent de si petites. De plus, sa cartographie pose problème. Henri Fréville, Julien Ricommard et plus récemment Claude Nières et Yann Lagadec s'opposent sur le nombre de subdélégations à retenir ${ }^{4}$. Tous ont lu les mêmes sources, regroupées pour la plupart dans le premier carton de la série $\mathrm{C}$ des archives départementales d'Ille-et-Vilaine. S'y trouvent notamment plusieurs manuscrits listant les subdélégations qu'il est possible, à partir des noms de subdélégué cités, de dater des années 1712$1713,1726-1729,1729,1736$ et $1781-1784^{5}$. Incertitudes et erreurs ont eu le mérite de susciter réflexions et analyses sur le nombre et la répartition des subdélégations bretonnes. L'ensemble administratif est alors compris soit comme un réseau, soit comme un maillage. Les deux approches sont justifiées car l'intendance développe bien un réseau de correspondants qui devient permanent et se fixe dans un maillage territorial.

Les subdélégations doivent être abordées comme des territoires construits progressivement et il convient de s'interroger sur les ressorts de cette construction. Elle semble d'abord découler des exigences stratégiques de l'intendance à l'origine du premier réseau de subdélégués mais les circonscriptions sont ensuite modelées lors de négociations avec les subdélégués. Surtout, elles sont régulièrement remises en question face à l'organisation pratique de l'administration à l'échelle de l'intendance mais aussi des subdélégations.

\section{Un réseau de subdélégués}

Les subdélégués forment un réseau centralisé par l'intendant. Simples correspondants au départ, ils sont devenus de véritables administrateurs recevant ses ordres et envoyant leurs comptes rendus; ils entretiennent une correspondance régulière avec son hôtel. Leur répartition sur le terri-

4. FRÉVILLE, Henri, L'intendance de Bretagne..., op. cit., vol. 1, p. 112. RICOMMARD, Julien, "Du recrutement et du nombre des subdélégués en titre d'office dans l'intendance de Bretagne (1704-1715) ", Revue d'histoire moderne et contemporaine, 1961, p. 148. NiÈRES, Claude, Les villes de Bretagne, conditions et formes de développement urbain au XVIII siècle, [thèse d'histoire, université de Paris IV, 1987], Rennes, PUR, 2004, p. 412-413. LaGADEC, Yann, "Penser l'espace administratif pour le moderniser, L'exemple des subdélégations en Bretagne au XVIII ${ }^{e}$ siècle ", dans CAULIER, Brigitte et Rousseau, Yvan (dir.), Temps, espaces et modernités, mélanges offerts à Serge Courville et Normand Séguin, Québec, PUL, 2009, p. 313.

5. Arch. dép. d'Ille-et-Vilaine, C1 et C6060(2). Pour le détail de la datation : DidiER, Sébastien, Les subdélégués des intendances de Bretagne et de Nouvelle-France..., op. cit., vol. 1, p. 40-42 et vol. 2, annexe ${ }^{\circ}$ 21, chronologie des subdélégués de Bretagne, p. 169. 
toire provincial ne relève aucunement du hasard; elle répond d'abord aux besoins de l'intendant et ne se comprend pas sans une certaine connaissance des prérogatives des subdélégués et de leur évolution.

\section{Du correspondant à l'administrateur}

Officieuse, la subdélégation laisse peu de traces avant l'édit royal de 1704 ; il est donc difficile de bien cerner la situation des premiers subdélégués. Selon Julien Ricommard, dans la plupart des intendances, créées dans les années 1620, les subdélégués apparaissent de manière pérenne dès les années $1660^{6}$. Les intendants commencent par développer un réseau de correspondants pour être informés, puis, ayant établi une relation de confiance avec eux, leur subdélèguent progressivement leurs pouvoirs. Dans la jeune intendance bretonne, il est fort possible que l'intendant nomme des subdélégués dès le début, même s'il utilise la dénomination de " correspondant " pour ne pas froisser le ministre, opposé par principe à la subdélégation. En 1689, Auguste Robert de Pomereu, le premier intendant de Bretagne, "établit ainsi des "correspondants" aux sièges des évêchés, des sénéchaussées, dans la plupart des centres de quelque importance " selon Julien Ricommard ${ }^{7}$. Dans une lettre d'août 1691 citée par Henri Fréville, il indique qu'il dispose de " commis attachés à diverses villes (Morlaix et Saint-Malo, par exemple); qu'un autre, Révillois, circule dans toute la province ${ }^{8}$ ". Ces premiers subdélégués sont désignés pour des missions précises, ponctuelles dans l'espace et le temps. Sébastien Frain de La Villegontier est ainsi commis le 13 juin 1696 pour faire l'adjudication au rabais des réparations d'un pont de Fougères ${ }^{9}$. Bréart, sieur de la Laignière, est nommé à Brest en 1692 et Jean Emmanuel de La Boissière à Guérande en $1694^{10}$. Ces subdélégués ponctuels exercent plusieurs fois et deviennent les premiers subdélégués permanents de ces localités. Auguste Robert de Pomereu délivre déjà des commissions permanentes pour différentes matières aux subdélégués de Nantes, Vannes, Quimper mais également pour Jean-Baptiste Primaignier à Redon et Sébastien Frain à Fougères ${ }^{11}$. Ensuite, à la lecture des lettres de provisions adressées aux subdélégués en titre d'office, J. Ricommard relève 34 subdélégués par commission continués dans leurs fonctions après l'édit de $1704^{12}$. Au moins 34 subdéléga-

6. RicommaRD, Julien, « Les subdélégués des intendants... », art. cit., p. 139-146.

7. Ricommard, Julien, «Les subdélégués en titre d'office et leurs greffiers dans l'intendance de Bretagne (1704-1715) ", Annales de Bretagne, 1960, p. 261.

8. FREVILLE, Henri, L'intendance de Bretagne..., op. cit., vol. 1, p. 62.

9. Arch. dép. d'Ille-et-Vilaine, C 379 , bail de l'adjudication des réparations du pont Graffard, 19 juin 1696.

10. TrIPIER, Yves, " Les origines sociales des subdélégués brestois ", Bulletin de la Société Archéologique du Finistère, t. CVII, 1979, p. 243 et sq. Pelletreau, Béatrice, Les subdélégués des intendants dans le comté nantais aux XVII et XVIII siècles, mémoire de maîtrise, univ. Nantes, 1988, p. 83.

11. RICOMMARD, Julien, " Les subdélégués en titre d'office... ", art. cit., p. 265 et 272.

12. Ibidem, p. 450-455. 
tions existaient donc avant 1704 et probablement plus, sinon, pourquoi attribuer à sept d'entre elles un double ou triple chef-lieu (figure 1)?

L'édit d'avril 1704 officialise la subdélégation dans tous les sens du terme puisqu'il légifère sur la " création en titre d'office formé et héréditaire d'un conseiller subdélégué des sieurs intendants [...] dans chacun chef-lieu [...] où il en a été étably jusqu'à présent, ou dans lesquelles l'établissement en paroistra nécessaire ${ }^{13}$ ". La vente d'offices doit permettre de donner plus d'autorité aux subdélégués et d'accroître leur motivation face à des tâches de plus en plus nombreuses ${ }^{14}$; elle doit aussi nourrir le trésor royal affaibli par les guerres. L'intendant de Bretagne envoie au ministre une liste de chefs-lieux afin que soient mis aux enchères les offices correspondants. 38 sont créés. Cependant, les subdélégués rechignent à les acquérir ${ }^{15}$. En 1715, alors que le Conseil du roi revient sur l'édit et rétablit la nomination par commission, quinze subdélégués n'ont toujours pas achevé de financer leur office ${ }^{16}$; parmi eux, douze n'ont rien versé. Comme ils avaient la confiance de l'intendant, leur poste ne pouvait être confié à un autre. De plus, ne pas payer n'empêche pas d'exercer puisque plusieurs autres subdélégués travaillent officieusement comme Pierre Jaffrezic de Kerhorre à Pontrieux et Jean-Louis Anger de La Haye à Bazouges-la-Pérouse dès $1710^{17}$. En 1713, un document nous permet de compter 87 subdélégations bretonnes. L' "État contenant le nom des subdélégués et les paroisses de leurs départements desquelles ils ont fait fournir les déclarations pour le dixième " liste 82 groupes de paroisses ${ }^{18}$. Elles correspondent, comme l'indique Julien Ricommard corrigeant les interprétations d'Henri Fréville, à des départements créés spécialement pour la collecte de l'impôt ${ }^{19}$. Seulement, l'intendant a fait noter en face de chaque paroisse son cheflieu de subdélégation. Parfois subdélégation et département du dixième correspondent comme pour Redon, Châteaubriant ou Lesneven mais, en général, les chefs-lieux de subdélégation indiqués diffèrent du siège du département fiscal. 84 subdélégations sont mentionnées auxquelles il faut ajouter la deuxième subdélégation de Rennes confondue avec la première dans le document et les subdélégations de Port-Louis et Ingrandes trop petites pour être notées avec leur unique paroisse. Déjà en 1713, la province est découpée en 87 subdélégations, comme dans l'« État d'arrondissement général des subdélégations de la province de Bretagne " daté de 1729.

13. Arch. dép. d'Ille-et-Vilaine, 1A 10, édit du Roi, avril 1704.

14. RicommaRD, Julien, "Les subdélégués des intendants... ", art. cit., p. 190.

15. RicommARD, Julien, "Les subdélégués en titre d'office... », art. cit., p. 255-308, 1961, p. 437-472, 1962, p. 305-341.

16. Arch. dép. d'Ille-et-Vilaine, C 1831, état du recouvrement de la finance des offices de subdélégués de l'intendant de Bretagne, août 1715.

17. Arch. dép. d'Ille-et-Vilaine, C 2605, ordonnance de l'intendant Ferrand, juillet 1710.

18. Arch. dép. d'Ille-et-Vilaine, C 1.

19. RicommaRD, Julien, " Du recrutement et du nombre des subdélégués... ", art. cit., p. 148. 

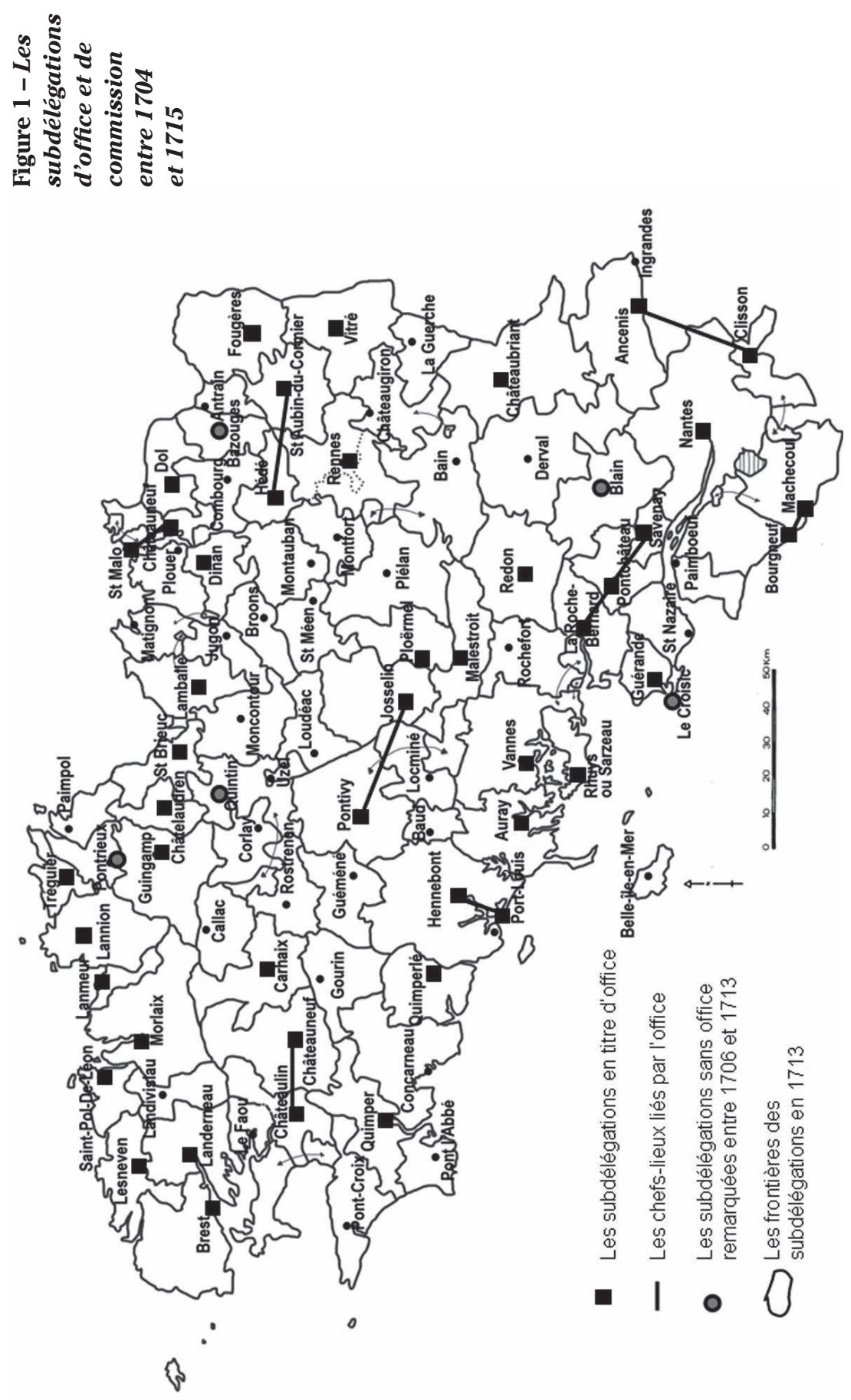


\section{Une répartition stratégique}

Avec 87 chefs-lieux, l'intendant de Bretagne cherche à couvrir l'ensemble de la province le plus efficacement possible. Le réseau de subdélégués quadrille le territoire de manière presque régulière, même s'il est moins resserré dans les diocèses de Nantes et Quimper, légèrement moins densément peuplés. En 1775, l'intendant Caze de La Bove explique le nombre important de subdélégations par la mauvaise qualité des chemins et les difficultés de communication du début du siècle, la volonté de " diminuer l'embarras de chacun en les partageant au plus grand nombre" et la pression des gentilshommes locaux pour obtenir cette fonction ${ }^{20}$. Les subdélégués ne sont pas rémunérés et ne peuvent consacrer tout leur temps à la subdélégation. Cependant, toute la Bretagne doit bénéficier de leur service, surtout quand il est question de répartir l'impôt ou de lever de la milice ${ }^{21}$. Surtout, l'intendant souhaite être tenu informé sur chaque village de la province. La force de son réseau tient donc à l'efficacité de la correspondance. Ce dernier est pensé en fonction du réseau routier. Aussi, toutes les " villes carrefours", comme les appelle Claude Nières ${ }^{22}$, sont-elles choisies pour chef-lieu de subdélégation (figure 2). D'autres sont plutôt des " villes étapes " comme Bain et Derval sur la route de Rennes à Nantes ou Montauban et Broons sur celle de Rennes à Lamballe. À partir de 1738, la mise en place de relais de poste à chevaux confirme cette logique de répartition : plus des deux-tiers sont installés dans des sièges de subdélégation. Cette répartition facilite la correspondance et donc le lien entre l'intendant et le subdélégué.

Les subdélégués contrôlent ainsi les points de passage. Dans une province frontière, comme la Bretagne, cette position est éminemment stratégique. Ils sont tous chargés de différents services logistiques de l'armée. Responsables de l'Étape, ils gèrent l'accueil des troupes en marche et répartissent, entre les communautés d'habitants, les coûts du logement des gens de guerre et leur approvisionnement en vivres, fourrages et fournitures. Plus régulièrement, ils fournissent aussi aux soldats isolés les moyens de rejoindre leur régiment, contrôlent leurs entrées et sorties des hôpitaux et distribuent les congés et retraites d'invalidité. Certaines subdélégations s'avèrent plus stratégiques encore; leur faible étendue en témoigne. Chargés de moins de dix paroisses, les subdélégués du Croisic, de PortLouis, de Saint-Malo, d'Ingrandes ou d'Antrain surveillent ces portes maritimes ou terrestres. Plus précisément, ils contrôlent l'action des employés

20. Arch. nat., H 613, mémoire concernant les subdélégués de l'intendance de Bretagne, 1775, cité dans FRÉVILLE Henri, L'intendance de Bretagne..., op. cit., vol. 3, p. 20-21.

21. Les subdélégués bretons s'occupent de la répartition de la capitation en 1695-1697 et 1701-1705, puis du dixième en 1710-1717 et 1733-1735 et enfin du vingtième en 1750-1757. Ils lèvent la milice partout sauf dans les paroisses garde-côtes.

22. NiÈRES, Claude, Les villes de Bretagne..., op. cit., p. 49. 

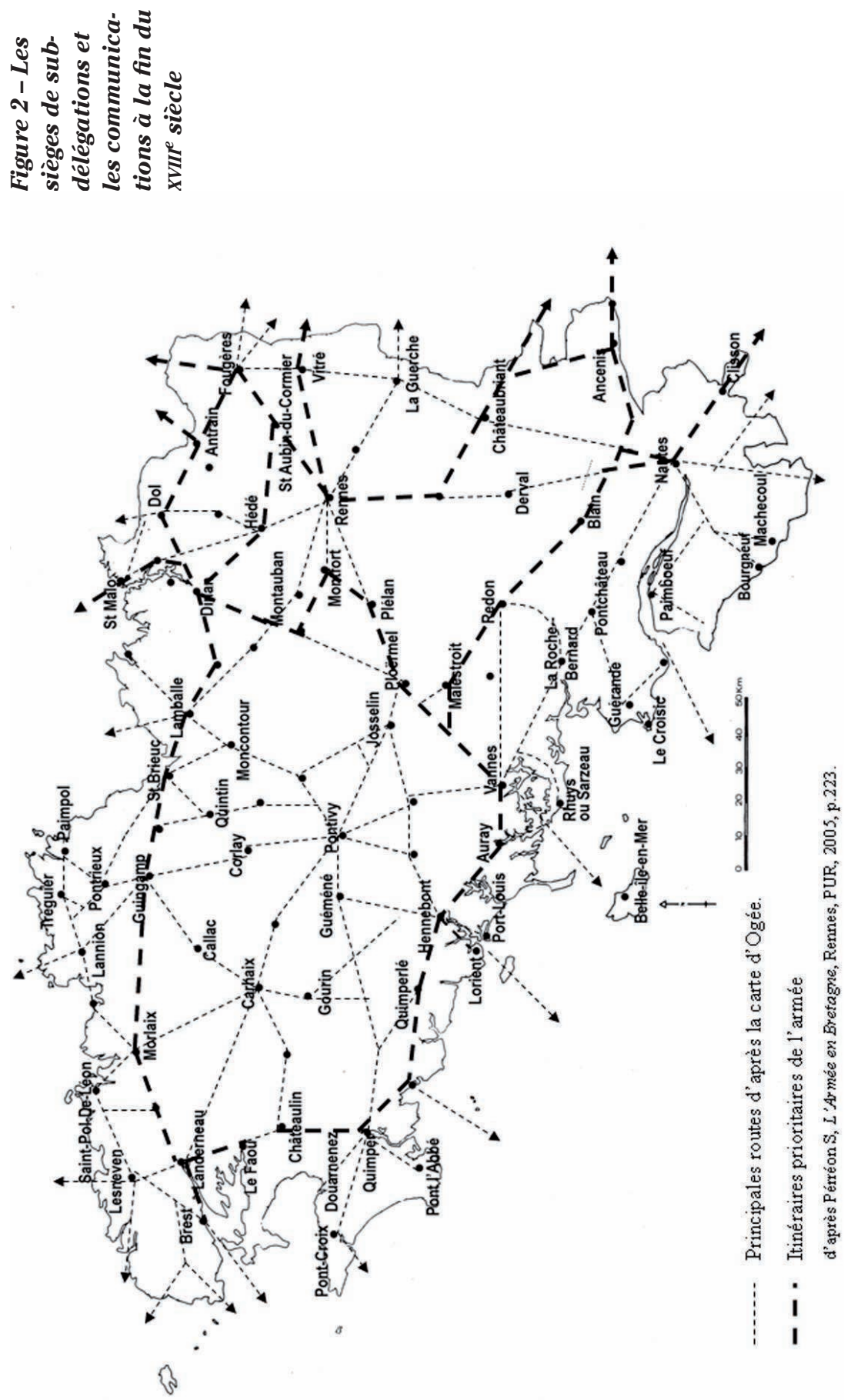
des fermes du Roi et des receveurs du Domaine en vérifiant leurs procèsverbaux de saisie de contrebande. Le nombre important de subdélégations se justifie donc aussi par le besoin de contrôler certaines zones sensibles.

Les subdélégations sont essentiellement implantées dans des villes de pouvoir et plus particulièrement dans les chefs-lieux de juridiction. Les 26 sièges de sénéchaussée accueillent un subdélégué au moins jusqu'en 1736. Dans le royaume, sur 434 bailliages et sénéchaussées, seuls 77, soit $18 \%$, ne sont pas des chefs-lieux de subdélégation ${ }^{23}$. En Bretagne, sont également toutes sièges permanents les 21 villes citées par Claude Nières comme relevant intégralement de la justice d'un seul seigneur ${ }^{24}$. De plus, la plupart des chefs-lieux de subdélégation sont aussi les sièges de nombreuses justices seigneuriales ou ecclésiastiques. Ce choix permet à l'intendant de se poser en contre-pouvoir face aux officiers et seigneurs les plus puissants de la province mais il est aussi imposé par le recrutement des subdélégués. En effet, le plus souvent, l'intendant choisit ses représentants parmi les magistrats; cette qualité l'assure de leurs compétences en matière de droit et de procédures administratives. Il privilégie également les chefs-lieux urbains. Le contrôle des finances des communautés urbaines impose la présence de subdélégués dans les 42 villes ainsi organisées. Dans les autres provinces, la vérification et la liquidation des dettes des communautés ordonnées en octobre 1662 marquerait une étape importante dans le développement et la territorialisation de la subdélégation ${ }^{25}$. En Bretagne, comme 38 d'entre elles députent aux États provinciaux, leur surveillance permet aussi à l'intendant de garder un œil sur ce contre-pouvoir embarrassant.

\section{Un réseau concurrencé}

La croissance du pouvoir de l'assemblée provinciale entraîne en 1736 une grande restructuration du réseau de subdélégués ${ }^{26}$. Déjà, en 1705 , la répartition et la levée de la capitation leur échappent. En 1732, les États obtiennent en plus l'administration de l'Étape; ils s'organisent alors en créant un réseau de correspondants sur tout le territoire. À la session suivante, en 1734, ils créent une " commission intermédiaire " assurant la permanence de leur pouvoir entre deux réunions. Ainsi renforcés, ils négocient et obtiennent dès l'année suivante l'abonnement et la levée de l'impôt du dixième. Ce transfert de prérogatives entre subdélégués et correspondants de la Commission intermédiaire amène l'intendant à supprimer 24 subdélégations, soit plus d'un quart de son réseau.

23. ARbellot, Guy, GouBert, Jean-Pierre (dir.), Carte des généralités, subdélégations..., op. cit., p. 15.

24. NIĖRES, Claude, Les Villes de Bretagne..., op. cit., p. 439. Il cite l'intendant Béchameil de Nointel.

25. RicommarD, Julien, « Les subdélégués des intendants... », art. cit., p. 147.

26. À propos des pouvoirs des États de Bretagne, voir RéBlLLoN, Armand, Les États de Bretagne de 1661 à 1789. Leur organisation, l'évolution de leurs pouvoirs, leur administration financière, Paris et Rennes, A. Picard, 1932. 
En 1736, dès sa première année d'exercice, l'intendant Jean-Baptiste de Pontcarré de Viarmes décide de ne conserver que les subdélégations les plus stratégiques. Il allège le réseau de plusieurs "villes étapes " comme Rostrenen, Loudéac ou Savenay, mais conserve les " villes carrefours "; il délaisse surtout des chefs-lieux de juridictions seigneuriales, mais aussi de petits sièges royaux : Bazouges-la-Pérouse, Jugon, Châteauneuf, Châteaulin, Gourin et Concarneau. Par contre, il conserve le contrôle de toutes les communautés de ville. Certaines de moins de 1000 habitants, comme Hédé, Pont-l'Abbé ou Montfort, sont maintenues comme subdélégation à cause de ce statut urbain. D'ailleurs, dès que Lorient l'obtient en 1741, l'intendant y commet Thimeur de Montigny. Ces représentants sont désormais plus nombreux sur les côtes que dans l'intérieur de la province; les minuscules subdélégations de Belle-Île, de Sarzeau et du Croisic sont conservées alors que, sur le continent, celles de Baud et Uzel ne persistent pas. Le commissaire départi conserve ainsi le contrôle des ports. Le maintien d'un grand nombre de subdélégations sur la côte se comprend aussi à cause de l'importance de la population littorale. En 1770, la densité dépasse les 75 habitants au $\mathrm{km}^{2}$ au nord des diocèses de Saint-Pol-de-Léon et de Tréguier ${ }^{27}$; cette région garde d'ailleurs le même nombre de subdélégations. À l'inverse, sur les côtes des diocèses de Vannes, Nantes et Saint-Brieuc, un plus faible peuplement explique la suppression de Rochefort, Saint-Nazaire et Matignon. Réduit à 63 subdélégations en 1736, le réseau évolue encore avec la création des subdélégations de Lorient en 1741 et peut-être celle de Douarnenez dans les années 1780.

Mis en place dans les années qui suivent la création de l'intendance en 1689 et en partie officialisé en 1704, le réseau de " correspondants " de l'intendant de Bretagne est rapidement devenu un réseau de chefs-lieux. Son organisation et son évolution dépendent des fonctions confiées aux subdélégués. D'abord ponctuelles, leurs missions deviennent régulières et permanentes entraînant ainsi le développement d'un nouveau cadre administratif.

\section{Un nouveau territoire à construire}

La territorialisation des subdélégations bretonnes est tout à fait originale. Sans reprendre d'anciens cadres administratifs, l'intendant a créé de nouvelles circonscriptions en négociant avec ses subdélégués. Le maillage ainsi dessiné présente une grande variété de formes orientant les pratiques administratives.

\section{Créer un nouveau cadre administratif}

La coutume, déjà suggérée dans l'édit d'avril 1704, veut que les subdélégations correspondent aux élections dans les pays taillables et aux

27. CROIX, Alain, Neveu, Roland, Les Bretons et Dieu : atlas d'histoire religieuse, Rennes, PUR, 1980, carte ${ }^{\circ} 4$. 
bailliages dans les pays d'États ${ }^{28}$. Cependant, rien n'est imposé et l'organisation de la province peut varier, comme l'indique René Grevet, " en fonction de l'appréciation des intendants ${ }^{29}$ ". Si, dans les autres provinces, "le ressort du subdélégué correspond généralement à celui de la compagnie à laquelle il appartient ${ }^{30}$ ", les subdélégués bretons doivent souvent couvrir des ressorts bien distincts. Leur nombre et leur diversité ont poussé les intendants à créer de toutes pièces de nouveaux cadres administratifs. Certes, à Concarneau, Quimperlé et Gourin, les subdélégations correspondent aux sénéchaussées mais, à Auray, Antrain et Fougères, les magistrats subdélégués doivent faire attention à certaines paroisses intégrées dans leur subdélégation mais pas dans leur juridiction et inversement. Ailleurs des situations bien plus complexes se présentent. La subdélégation de Redon est à cheval sur trois sénéchaussées relevant de trois présidiaux différents : Ploërmel, Rennes et Nantes; le subdélégué de Hédé est responsable de 15 paroisses de la sénéchaussée de Hédé, quatre de la sénéchaussée de Rennes et d'une autre de la sénéchaussée de Dinan. De son côté, le sénéchal de Hédé a des pouvoirs judiciaires sur un territoire à cheval sur 5 subdélégations : Hédé, Combourg, Montauban, Bazouges et Rennes. Même si l'intendant avait voulu associer les ressorts de ces officiers avec leur subdélégation, il n'aurait pu, du fait de la diversité de leurs fonctions. Beaucoup exercent dans les juridictions royales, beaucoup également dans les juridictions seigneuriales, d'autres, plus rares, dans les bureaux de la Marine. Parfois, comme à Fougères ou à Saint-Malo, l'intendant commissionne le maire. Sans base administrative cohérente, les subdélégations doivent être construites.

De ce fait, la délimitation des subdélégations bretonnes ne va pas de soi et fait l'objet d'un bricolage territorial. Julien Ricommard donne l'exemple caractéristique de la lettre de provision du subdélégué à Vitré qui se voit attribuer " la ville de Vitré, et estendue de la baronnie et jurisdiction dudit Vitré, paroisses de Bays, Monville et Espinay en dépendantes ${ }^{31}$ ". Ce ressort est tellement neuf qu'il faut faire appel à trois types de circonscriptions territoriales pour le définir : la ville, la juridiction seigneuriale et les paroisses. Loin de s'imposer, le nouveau territoire s'est probablement immiscé très lentement dans les cartes mentales de la population. Les subdélégués eux-mêmes ne maîtrisent pas tous parfaitement leur département avant 1729. Sébastien Frain distingue les paroisses qui devraient faire partie de son département et celles « qu'on joint ordinairement à la subdélégation

28. . Arch. dép. d'Ille-et-Vilaine, 1A 10, édit du roi donné à Versailles, avril 1704.

29. GREVET, René, "Être subdélégué d'intendant dans les provinces septentrionales à la fin du XVIII ${ }^{e}$ siècle ", Bulletin de la Société d'histoire moderne et contemporaine, 1998-3/4, p. 15.

30. RicommaRD Julien, « Les subdélégués en titre d'office... », art. cit., p. 274.

31. Arch. nat., $\mathrm{V}^{1} 173$, cité par RicommarD, Julien, « Du recrutement et du nombre des subdélégués..." ", art. cit., p. 145. 
de Fougères à cause de leur proximité ${ }^{32}$ "; il présente à l'intendant sept paroisses dont il s'occupe habituellement bien qu'elles soient de la baronnie de Vitré. Il y aurait donc le territoire de la pratique passée et un autre reposant plutôt sur des principes théoriques. Cette division de l'espace en grands ensembles seigneuriaux compte donc encore dans les représentations de l'espace. À l'inverse, il semble se tromper en intégrant dans son ressort plusieurs paroisses associées en 1713 et 1729 dans les départements d'Antrain et Saint-Aubin-du-Cormier. Ces erreurs sont compréhensibles, d'autant plus qu'un certain nombre de paroisses ne relevant pas de sa subdélégation lui avaient été confiées pour la levée du dixième en 17121713. Il évoque également deux paroisses jointes " pour la dernière levée des soldats de milice ${ }^{33}$ ". Avant 1729, les subdélégations sont peut-être à comprendre comme un chef-lieu dominant une étendue fluctuant suivant le service demandé ou l'intendant le demandant. Le subdélégué à Carhaix le laisse supposer, "n'ayant jamais eu un arrondissement fixe ${ }^{34}$ ".

\section{Fixer le ressort, un travail collectif}

En décembre 1728, le nouvel intendant Jean-Baptiste des Gallois de La Tour souhaite clairement fixer les circonscriptions des subdélégués. Il demande alors à chacun de lui envoyer une liste des " paroisses, trèves $\&$ frairies qui composent [leur] subdélégation, pour pouvoir [leur] adresser les affaires qui les concernent, [...] en observant de n'y comprendre que celles qui sont en effet de [leur] département, \& de n'en obmettre aucune $^{35}$ ". Il leur donne ainsi à tous l'occasion de lui faire part de leurs doutes, réclamations et revendications concernant leur circonscription. Le subdélégué de Fougères, cité ci-dessus, ne souhaite plus lever la milice dans deux paroisses trop éloignées de son chef-lieu. Après avoir tenu compte de toutes les réponses, l'intendant leur renvoie leur liste de paroisses définitives. Certains contestent. Le Gallo, à Brest, revendique cinq paroisses confiées au subdélégué de Lesneven ${ }^{36}$; Duboys, à Pontivy, refuse trois paroisses éloignées qui " doivent-être [dit-il] naturellement attachées à la subdélégation de Lominé ${ }^{37}$ ". Pour son secrétaire, Jean-Baptiste des Gallois annote la lettre de Duboys : «R[épondre] le 25 mars 1729 que ces trois

32. Arch. dép. d'Ille-et-Vilaine, C 1, état des paroisses de campagne dépendant de la subdélégation de Fougères.

33. Arch. dép. d'Ille-et-Vilaine, C 1, état des paroisses de campagne dépendant de la subdélégation de Fougères.

34. Arch. dép. d'Ille-et-Vilaine, C 1503, lettre du subdélégué de Carhaix, 6 mars 1729, citée dans Duval, Jacques, Moulins à papier de Bretagne du XV $T^{e}$ au XIX siècle. Les papetiers et leurs filigranes en Pays de Fougères, Paris, L'Harmattan, 2005.

35. Arch. dép. d'Ille-et-Vilaine, C 1, texte imprimé de l'intendant adressé aux subdélégués, 29 décembre 1728 .

36. Arch. dép. d'Ille-et-Vilaine, C 1, état des paroisses de la subdélégation de Brest arrêté par de La Tour en février 1729 et renvoyé à l'intendant par Le Gallo en mars 1729 .

37. Arch. dép. d'Ille-et-Vilaine, C 1, lettre de Duboys à l'intendant de La Tour, Pontivy, mars 1729 . 
$\mathrm{p}$ [aroi]sses ont toujours été du département de Pontivy, au surplus que l'arrondisse[ment] est arresté et qu'il n'y a plus moyen de changement ${ }^{38}$."

En grande majorité, les subdélégués acceptent leur liste car les changements sont mineurs (cf. annexes). En Haute-Bretagne, entre 1713 et 1729, le département de Dinan perd la paroisse de Saint-Helen au profit de Combourg. Montauban donne trois paroisses à la subdélégation de Broons, Montfort deux à celle de Rennes et Nantes deux à celle de Savenay. En Basse-Bretagne, Brest perd quatre paroisses qui deviennent des enclaves de Lesneven et Lanmeur gagne deux paroisses de Lannion. L'ensemble des subdélégués a répondu correctement permettant ainsi de conserver, à quelques paroisses près, les étendues relevées en 1713. Pour sa part, le nouvel intendant préfère probablement dans un premier temps faire confiance aux outils de ses prédécesseurs et à un réseau qui a fait ses preuves par la pratique. En même temps, en s'adressant aux subdélégués pour concevoir leur département, il entre en contact avec eux et gagne leur confiance en les associant au projet. Les circonscriptions ainsi fixées, l'intendant produit un registre récapitulatif : l'«État d'arrondissement général des subdélégations de la province de Bretagne ${ }^{39}$ ". "Pour la première fois, nous trouvons un répertoire sérieux et complet ", commente Henri Fréville ${ }^{40}$.

\section{Une grande variété de formes}

Les subdélégations fixées par l'intendant sont de tailles et de formes très variées. Les plus petites ne comptent qu'une paroisse; la plus grande en comprend 46 en 1729, 58 en 1736. À cette date, 32 subdélégations absorbent les 24 supprimées mais 31 n'évoluent pas. Vers 1770, celles de Saint-Malo, Paimpol ou Tréguier connaissent une densité démographique oscillant entre 50 et plus de 200 habitants $/ \mathrm{km}^{2}$ suivant les paroisses, alors que les 50 habitants $/ \mathrm{km}^{2}$ ne sont dépassés par aucune paroisse des subdélégations de Pontivy, Blain et Plélan ${ }^{41}$. Les chefs-lieux de Nantes, Rennes, Saint-Malo ou Brest accueillent plusieurs dizaines de milliers d'habitants urbains, alors que ceux des subdélégations d'Antrain, Clisson ou Carhaix en comptent moins de $2000^{42}$. Avant 1736, de nombreux subdélégués vivent même dans de petits bourgs comme Châteauneuf, Locminé, Pontchâteau ou Saint-Nazaire.

De ce panel de formes découlent de grandes différences de recrutement. De 1689 à 1789, se succèdent entre 2 et 15 subdélégués suivant la subdélégation. Au-dessus de la moyenne de cinq subdélégués successifs, beaucoup de circonscriptions urbaines comme Brest, Saint-Malo ou

38. Arch. dép. d'Ille-et-Vilaine, C 1, lettre de Duboys à l'intendant de La Tour, Pontivy, mars 1729 .

39. Arch. dép. d'Ille-et-Vilaine, C 1.

40. . FreVILle, Henri, L'intendance de Bretagne..., op. cit., vol. 1, p. 311.

41. Croix, Alain, Neveu, Roland, Les Bretons..., op. cit., carte 4.

42. NiÈRES, Claude, Les villes de Bretagne..., op. cit., p. 560. 
Nantes connaissent de brèves subdélégations. À Nantes, les subdélégués sont, pour la plupart, échevins et occupent un moment la mairie; à SaintMalo, quatre subdélégués se succèdent même tous les trois ans à chaque élection de 1757 à 1773. En milieu rural, comme à Pontchâteau, Antrain ou Pontrieux, les subdélégations s'allongent. Même si rien n'est systématique, l'intendant remplace couramment ses subdélégués ruraux par la personne que ces derniers lui conseillent. Ainsi, le fils succède-t-il au père dans les familles Anger à Antrain ou Cocaud à Blain. Lorsqu'il n'est pas de la même lignée, le successeur occupe souvent le même office de magistrature. À Saint-Aubin-du-Cormier, chaque sénéchal s'occupe de la subdélégation. À Hédé en 1721, la succession se fait de manière assez remarquable : à la mort du sénéchal et subdélégué, son fils n'est pas encore assez vieux pour juger, la subdélégation revient au procureur du roi qui prend l'intérim de la juridiction pendant deux ans; à sa mort, elle passe de la même manière entre les mains d'un juge seigneurial. En milieu rural, il n'est pas rare que le subdélégué provienne d'une notabilité moins prestigieuse : Joubaire de La Drutais à Plélan-Le-Grand entre 1770 et 1780, Jacques Royou à PontL'Abbé entre 1766 et 1785 ou Pierre Primaignier à Redon entre 1734 et 1762 sont de simples procureurs fiscaux. À Rennes, au contraire, beaucoup sont conseillers au présidial.

Reflets de leur subdélégation, les subdélégués ne sont pas égaux. Même les Bretons n'accordent pas à tous la même importance. À partir de 1762, les Étrennes bretonnes commencent à relever leurs noms pour les publier. Malgré quelques erreurs et une faible réactualisation de leurs informations laissant croire à de très longues commissions, les Étrennes ont le mérite de montrer la considération croissante des Bretons pour les subdélégués ${ }^{43}$ En 1770, ils apparaissent tous dans cet annuaire, soit au chapitre de l'intendance, soit à celui des " principales villes "; les plus importants figurent dans les deux. Encore une fois, les subdélégués des grandes villes semblent prépondérants (figure 3).

La territorialisation des subdélégations bretonnes est réalisée en plusieurs étapes. Déjà amorcée avant 1713, elle ne tient aucunement compte des autres maillages administratifs. Plus ou moins fluctuantes, les circonscriptions sont fixées en 1729 par Jean-Baptiste des Gallois de La Tour. La subdélégation commence alors à être considérée comme une étendue précise. Les confusions et hésitations du début du siècle ne sont plus permises aux subdélégués. En 1788, l'intendant Antoine-François de Bertrand de Molleville le rappelle :

" Ils doivent connoître à fonds, non-seulement les villes et bourgs, mais jusqu'aux moindres paroisses de leur subdélégation; leurs besoins, leurs res-

43. Étrennes bretonnes, géographiques, historiques, ecclésiastiques, civiles \&c. ou État abrégé de la Bretagne, Rennes, Julien-Charles Vatar, années 1762, 1768,1770, 1773-1775, 1777, 1779, 1782-1784, 1786, 1787, 1789. 

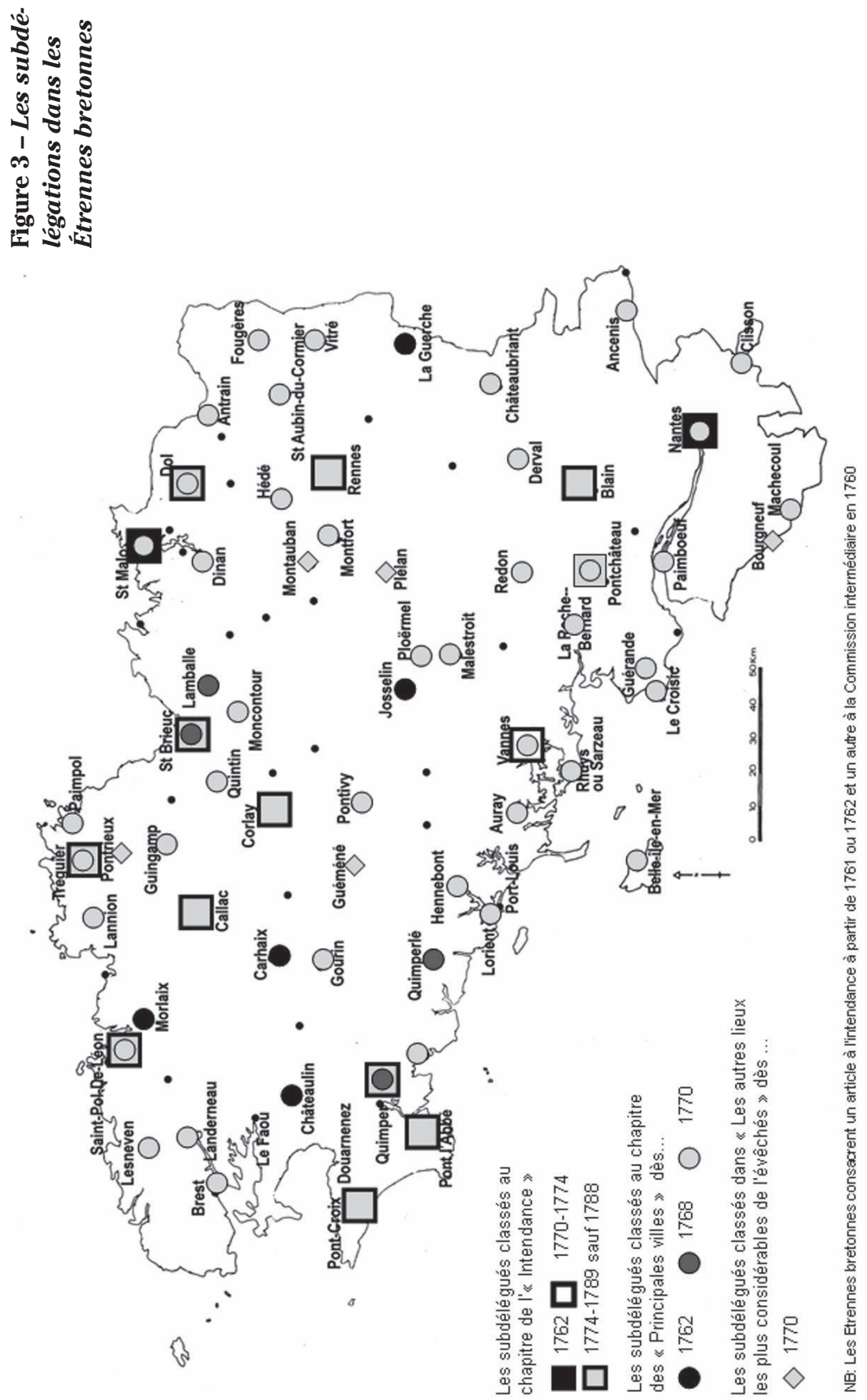
sources, leur industrie, les moyens de l'étendre et de la favoriser; la nature du sol et des productions, l'état de la culture et des défrichemens, les améliorations et les encouragemens dont ils sont susceptibles, leur population, le nombre des pauvres valides et les principaux propriétaires ${ }^{44}$."

\section{"Une étendue suffisante pour en bien remplir le service "}

Une telle familiarité avec leur circonscription paraît de plus en plus indispensable aux subdélégués. Leur rôle d'informateur croît et l'évolution de leurs fonctions pousse l'intendant à penser un nouveau projet de maillage administratif. Cependant, plusieurs conceptions du territoire s'opposent. Pour les habitants, la subdélégation reste avant tout liée au cheflieu qu'il faut conserver; l'intendant, pour sa part, la considère désormais comme une étendue et souhaite rationaliser le quadrillage de la province. Entre les deux, les subdélégués se sont appropriés leur département.

\section{L'organisation pratique des subdélégations}

Dans la pratique, une taille critique est associée aux subdélégations. En septembre 1781, Macé de La Porte refuse l'adjonction de deux nouvelles paroisses à son département lors du projet de suppression de la subdélégation de Derval. Il souhaite en effet que « Redon ait une étendue suffisante pour en bien remplir le service ${ }^{45}$ ". En décembre 1781, le subdélégué à Dol demande à l'intendant de rallier trois paroisses au département de Dinan et de les distraire du sien car elles sont trop éloignées de son chef-lieu ${ }^{46}$. Dans chaque état des paroisses des subdélégations, la distance au cheflieu, rarement supérieure à trois lieues, est sérieusement prise en compte : elle devait permettre " de s'y rendre dans la journée et ne pas excéder quelques heures aller-retour " selon Claude Nières ${ }^{47}$. L'intendant souhaite avant tout que le subdélégué travaille promptement. Or si ce dernier doit bloquer une journée entière ou même découcher pour faire une adjudication, faire afficher une ordonnance ou mener une enquête, il risque fortement de remettre ce travail à plus tard. De plus, la distance occasionne des frais souvent traduits en honoraires à la fin du siècle ${ }^{48}$. Pour le tirage de la milice, l'éloignement pèse plutôt sur les populations. En décembre 1780, le prince de Condé s'inquiète, face au plan de suppression de la subdélégation de Derval, des déplacements que ses vassaux devront endurer pour s'y

44. Bertrand de MolleVILle, Instructions pour MM. les subdélégués de Bretagne, Rennes, Chez la Veuve de François Vatar \& Bruté de Remur, imprimeur du Roi, 1788, p. 4.

45. Arch. dép. d'Ille-et-Vilaine, C 1, lettre de La Porte, subdélégué de Redon, à l'intendant, 8 septembre 1781 .

46. Arch. dép. d'Ille-et-Vilaine, C 1, lettre du subdélégué de Dol à l'intendant, décembre 1781 .

47. NiÈrEs, Claude, Les villes de Bretagne..., op. cit., p. 412.

48. BERTRAND de MOLLEVILLE, Instructions pour MM. les subdélégués..., op. cit., p. 65-66. 
rendre $^{49}$. En 1788, la même raison est évoquée par les prieur et religieux de l'abbaye de Saint-Gildas, pour demander le transfert de cette paroisse de la subdélégation de Blain à celle de La Roche-Bernard. L'éloignement du chef-lieu fait alors " perdre deux et trois journées de travail tant pour aller que pour revenir ${ }^{50} "$.

L'organisation interne de la subdélégation permet de réduire ces distances. Pour se défendre contre les revendications du subdélégué de Dinan sur quatre de ses paroisses, Jan de la Hamelinaye, subdélégué à Montauban, explique l'usage de centres secondaires. En effet, pour éviter que les garçons découchent, il respecte

" la règle qui [lui] est prescrite dans le cas du trop grand éloignement des paroisses. En conséquence [il] fait tirer à Becherel, St Jouan-de-lile, Broons et St-Méen. [...] Du reste, [il a] toujours soin d'expédier les paroisses éloignées les premières, l'opération à leur égard est finie dès les 10 heures du matin au plus tard; ce qui leur donne un temps suffisant pour venir et s'en retourner sans découcher ${ }^{51} "$.

Or cette pratique n'est pas exceptionnelle et ne s'applique pas qu'au tirage de la milice. Souvent, les subdélégués comptent même sur des centres hebdomadaires comme les foires et marchés. En décembre 1781, quand le subdélégué de Dol demande à l'intendant de rattacher au département de Dinan trois paroisses de sa subdélégation, il se justifie " par le grand nombre de leurs habitants qui se trouvent au marché de Dinan " contrairement à celui de Dol « où souvent on ne trouve aucun de leurs habi$\operatorname{tants}^{52}$ ». De même, Jan de La Hamelinaye présente le marché de Bécherel " comme l'entrepôt d'où [il] fai[t] partir les ordres dans les paroisses voi$\operatorname{sines}^{53}$ ". Lieux de rencontre et de sociabilité, les marchés structurent la circonscription. Les subdélégués s'y rendent souvent pour relever les prix du grain et du pain, pour publier les ordonnances, édits et divers règlements émanant du roi ou de l'intendance. Comme les juges de paix du Midi toulousain au XIX ${ }^{\mathrm{e}}$ siècle, ils devaient choisir le jour de marché pour rendre l'administration de l'intendance accessible aux habitants ${ }^{54}$.

Chaque subdélégué développe également son propre réseau de correspondants. Recteurs de paroisses ou autres notables locaux sont régu-

49. Arch. dép. d'Ille-et-Vilaine, C 1, lettre du prince de Condé à l'intendant de Bretagne, décembre 1780 .

50. Arch. dép. d'Ille-et-Vilaine, C 1, lettre des prieur et religieux de l'abbaye de SaintGildas et du recteur et des principaux habitants de cette paroisse à l'intendant, janvier 1788.

51. Arch. dép. d'Ille-et-Vilaine, C 1, lettre de Jan de La Hamelinaye à l'intendant, janvier 1782.

52. Arch. dép. d'Ille-et-Vilaine, C 1, lettre du subdélégué de Dinan à l'intendant, décembre 1781.

53. Arch. dép. d'Ille-et-Vilaine, C 1, lettre de Jan de La Hamelinaye à l'intendant, janvier 1782 .

54. THOMAS, Jack, Le temps des foires. Foires et marchés dans le Midi toulousain de la fin de l'Ancien Régime à 1914, Toulouse, Presses universitaires du Mirail, 1993, p. 170-176. 
lièrement sollicités pour le renseigner sur une affaire ou répondre à une enquête. Ces correspondants restent-ils de simples informateurs ou forment-ils un nouvel échelon administratif en développement? Jan de La Hamelinaye se défend de l'usage "d'exprès qu'il faut payer ${ }^{55}$ ". Le sieur de Leissegues de Légerville, prétendant au poste de subdélégué au Faou, dénonce les coûts de correspondance entre le subdélégué à Châteaulin et " celui qui le substitue ici ${ }^{56}$ ". L'intendant lui-même encourage à la formation d'un réseau de correspondants, dans un projet de lettre aux subdélégués surchargés par la suppression de subdélégations voisines.

\section{Le projet de l'intendant Caze de La Bove}

En 1775, le nouvel intendant, Gaspard Louis Caze de La Bove, souhaite réduire encore plus le nombre de subdélégations pour passer de 64 à 20 ou 32 départements ${ }^{57}$. Les États provinciaux ont continué à gagner des prérogatives comme l'organisation de la corvée en 1754 ou l'adjudication des grands chemins. Celles des subdélégués ont évolué vers l'information et les secours aux populations. Les exigences dans la réactivité du réseau grandissent. Aussi, pour justifier la plupart de ses projets de suppression, l'intendant utilise-t-il cet argument : " ma correspondance de mes subdélégués m'étant trop multipliée, j'ai cru qu'il étoit du bien du service de la simplifier ${ }^{58} "$.

De plus en plus, l'intendant mobilise ses représentants pour mener des enquêtes sur l'ensemble de leur département afin de créer des outils d'information à l'échelle de la province. En plus des états bimensuels du prix des grains, des états mensuels du prix des principales denrées ${ }^{59}$, ils fournissent depuis 1757 un état semestriel des crimes dignes des peines afflictives. Le travail de compilation et de synthèse de l'intendant s'en trouve alors multiplié. Depuis déjà 1736, pour les évaluations annuelles de l'apparence puis du produit des récoltes, l'intendant ne tient compte que d'une quinzaine de subdélégations dans ses récapitulatifs. Cette sélection est probablement réclamée par le Contrôle général pour faciliter son travail cartographique ${ }^{60}$. En 1775, le premier recensement de l'évolution de la population bretonne pose, semble-t-il, de nombreux problèmes d'organisa-

55. Arch. dép. d'Ille-et-Vilaine, C 1, lettre de Jan de La Hamelinaye à l'intendant, janvier 1782.

56. Arch. dép. d'Ille-et-Vilaine, C 1, lettre de Leissegues de Legerville à l'intendant, mai 1784 .

57. Arch. dép. d'llle-et-Vilaine, C 1, lettre de Turgot à l'intendant de La Bove, juin 1775. (20 subdélégations); « Division des subdélégations sans beaucoup s'écarter de l'Enceinte des Évêchés " par Frignet, juillet 1775 (32 subdélégations).

58. Arch. dép. d'Ille-et-Vilaine, C 1 , plusieurs projets de lettres aux subdélégués supprimés.

59. Ce sont le pain, les fourrages, les légumes, les boissons, les viandes, les fibres et la cire.

60. Arch. dép. d'Ille-et-Vilaine, C 1651, lettre du contrôleur général à l'intendant de Bretagne, mai 1738. 
tion $^{61}$; en effet, il n'est pas reconduit avant 1779, date à laquelle il devient annuel. Surtout, il semble susciter le projet de Caze de La Bove; avec moins d'informateurs, l'intendant espère améliorer le travail de compilation de ses services.

Plus qu'une simple réduction, son projet cherche à faire correspondre les limites des subdélégations avec celles des diocèses. De taille à être perçue par le Roi, les évêchés constituent les principales entrées des synthèses de l'intendance. De nombreuses subdélégations relèvent de deux ou trois diocèses et sont alors classées dans le diocèse de leur chef-lieu. Le projet de « Division des subdélégations sans beaucoup s'écarter de l'enceinte des évêchés " comprend désormais les subdélégations comme des étendues, même s'il garde quelques réflexes de la conception précédente. En effet, la subdélégation de Quintin est, en quelque sorte, l'exception qui confirme la règle : "Bien que cette ville soit du diocèse de Saint-Brieuc, elle sera la résidence d'un subdélégué du diocèse de Quimper ${ }^{62}$. " Le cheflieu reste indispensable, pour des raisons de recrutement notamment, si bien qu'on est prêt à le séparer de son département pour allier l'ancienne logique à la nouvelle.

Réformer le réseau de subdélégués bretons semble impératif à l'intendant. Toutefois, il ne peut espérer réaliser son projet sans l'accord des intéressés et rédige donc deux ébauches de lettre pour les informer. Ces écrits n'ont probablement jamais été envoyés mais ils montrent comment l'intendant souhaitait négocier avec les acteurs de son réseau. Aux subdélégués supprimés, il précise qu'il ne s'agit nullement d'une sanction et insiste sur la nécessité d'une telle réforme. Aux subdélégués surchargés, il déclare souhaiter " attirer sur eux les grâces et les récompenses ${ }^{63}$ ". Malheureusement, ces grâces dépendent du Contrôle général des finances. Or Turgot refuse d'accorder " des traitements fixes en faveur de[s...] subdélégués à quelque nombre que [l'intendant] les réduit. L'exemple seroit de trop grande conséquence pour les autres provinces du Royaume dans la pluspart desquelles les fonctions des subdélégués sont plus étendues qu'en Bretagne ${ }^{64}$ ". Bloqué par le manque de fonds, le projet de Caze de La Bove ne sera pas appliqué. Y. Lagadec estime alors que « les subdélégations bretonnes illustrent parfaitement ce que furent, en ce domaine comme en d'autres, les dernières années de l'Ancien Régime, entre volonté de réforme et difficultés à les mettre en œuvre ${ }^{65}$ ".

61. Arch. dép. d'Ille-et-Vilaine, C 1404, états de l'évolution de la population dans les subdélégations en 1774, mai à septembre 1775 .

62. Arch. dép. d'Ille-et-Vilaine, C 1, « Division des subdélégations sans beaucoup s'écarter de l'enceinte des évêchés " par Frignet, juillet 1775.

63. Arch. dép. d'Ille-et-Vilaine, C 1, "projet de lettre aux subdélégués restans ".

64. Arch. dép. d'Ille-et-Vilaine, C 1, lettre de Turgot à l'intendant de La Bove, juin 1775.

65. LAGADEC, Yann, " Penser l'espace administratif ... ", art. cit., p. 320. 


\section{La défense des subdélégations}

Sans avoir les moyens d'une réforme globale du maillage administratif, l'intendant essaie de supprimer ces subdélégations au fur et à mesure que les occasions se présentent. En août 1776, Hennebont risque fort de perdre son siège de subdélégué au départ de Milloch pour raison de santé. En juin 1780, Caze de La Bove essaie de supprimer la subdélégation de Derval quand le subdélégué Potiron de Boisfleury, malade, demande à se retirer et propose son fils pour lui succéder. Bertrand de Molleville applique la même politique, avec Pontchâteau en 1785 et Paimboeuf en $1789^{66}$. L'intendant attend le départ de ces hommes et ne laisse passer aucune occasion. En novembre 1780, le subdélégué à Saint-Aubin-du-Cormier demande à pouvoir former son gendre dans l'optique de le voir lui succéder. L'intendant l'informe alors qu'il ne sera pas remplacé : sa subdélégation " étant entrée dans [s]on plan de réduction, [il] la supprimer[a] aussitôt qu['il] ne pourr[a] plus remplir les fonctions ${ }^{67}$ ".

En choisissant de ne pas remplacer ces subdélégués, l'intendant évite de s'opposer à ses représentants ; par contre, il doit faire face aux communautés qui prennent la défense du siège de subdélégation. Les exemples découverts dans le carton $\mathrm{C} 1$ des archives d'Ille-et-Vilaine ne sont pas nombreux mais témoignent toutefois de l'importance qu'a prise ce territoire aux yeux de ses habitants; ils ne le défendent pas seulement pour éviter les désagréments pratiques de l'éloignement du subdélégué mais aussi pour conserver l'aura que dégage sa présence autour de la ville. En 1776, la communauté de Hennebont, soutenue par le subdélégué sortant, Milloch, s'oppose à la suppression du siège de la subdélégation; elle obtient gain de cause en arguant de l'importance de la ville, de sa juridiction royale et de l'éloignement de la subdélégation de Lorient. Ailleurs, des logiques seigneuriales entrent aussi en ligne de compte. Quand le prince de Condé défend Derval en 1780, il dénonce l'influence du duc de Rohan dans le choix de conserver Blain ${ }^{68}$. Les rivalités sont rudes et parfois les pressions seigneuriales entraînent des incongruités territoriales; Yann Lagadec explique ainsi les " isolats" de Quintin et Corlay ${ }^{69}$. Les argumentaires des opposants rappellent les logiques d'origine du maillage territoriale. Le prince de Condé soutient le maintien d'une subdélégation à Derval au motif que cette ville est " située sur la grande route " de Rennes à Nantes, contrairement

66. Arch. dép. d'Ille-et-Vilaine, C 1 . Le recensement des évolutions de la population de 1787 semble concrétiser ces projets (C 1436). Cependant, les subdélégués concernés continuent de correspondre en tant que tels avec l'intendant jusqu'en 1790.

67. Arch. dép. d'Ille-et-Vilaine, C 1, brouillon de lettre de l'intendant au subdélégué de Saint-Aubin-du-Cormier, décembre 1780.

68. Arch. dép. d'Ille-et-Vilaine, C 1, lettre du prince de Condé à l'intendant, décembre 1780 .

69. Quintin et Corlay, comme une dizaine d'autres subdélégations, ont un territoire morcelé avec quelques paroisses isolées du chef-lieu par les circonscriptions voisines. Cf. Annexes et Lagadec Yann, "Penser l'espace administratif... ", art. cit., p. 317. 
à Blain " éloignée de 3 à 4 lieues de toute grande route ${ }^{70}$ ". En janvier 1781, un opposant à la suppression de celle de Saint-Aubin-du-Cormier insiste sur l'importance du subdélégué face aux gens de guerre qui n'entendent pas d'autre autorité ${ }^{71}$. Pour faire pencher l'intendant de son côté, il faut parler en ses termes et avancer les mêmes arguments que lui auparavant. La logique du chef-lieu rayonnant n'est donc pas si obsolète.

En fin de compte, aucune suppression n'aboutit avant 1790. Le maillage des subdélégations n'appartient plus au seul intendant. Toujours concertés, les subdélégués organisent à leur échelle le territoire administratif en s'appuyant sur des centres secondaires et un réseau de correspondants. Dans les années 1780, certains subdélégués profitent d'ailleurs de la dynamique pour demander quelques modifications de leur ressort. À Dol, François Louis Desrieux de La Turrie obtient le transfert d'une paroisse de son département vers la subdélégation de Dinan ${ }^{72}$. La correspondance de Jan de La Hamelinaye révèle en plus la pratique de négociations et accords ponctuels entre les subdélégués pour des échanges de paroisses ${ }^{73}$. Enfin, le territoire administratif est désormais défendu par des groupes d'administrés : alliés aux subdélégués, ils semblent empêcher les restructurations envisagées. Le projet de réduction parait même contredit dans les années 1780 par la création de la circonscription de Douarnenez portant à 65 le nombre de subdélégués bretons ${ }^{74}$. Malheureusement, cette subdélégation est peu documentée et les raisons de sa création à l'encontre des projets de l'intendance restent inconnues.

La construction territoriale des subdélégations bretonnes est l'œuvre de plusieurs intendants successifs. Toutefois, leur stratégie territoriale, déterminante au début, ne s'impose pas. Elle s'adapte aux pratiques et se négocie avec les subdélégués et les acteurs locaux qui s'approprient le nouveau territoire. L'intendant Louis Béchameil de Nointel pose les bases en créant un réseau serré de 87 subdélégués à la fin du XVII ${ }^{\mathrm{e}}$ et au début du $\mathrm{XVIII}^{\mathrm{e}}$ siècle. Mais rapidement, la répétition de leurs missions demande une répartition des paroisses. Après concertation avec ses subdélégués, Jean-Baptiste des Gallois de La Tour en fixe les étendues dans un registre en 1729. Les circonscriptions ainsi créées s'organisent suivant leur propre logique, pour répondre aux exigences du service de l'intendance. Prenant

70. Arch. dép. d'Ille-et-Vilaine, C 1, lettre du prince de Condé à l'intendant, décembre 1780 .

71. Arch. dép. d'Ille-et-Vilaine, C 1, lettre à l'intendant, janvier 1781.

72. Arch. dép. d'Ille-et-Vilaine, C 1, lettre du subdélégué de Dol à l'intendant, décembre 1781.

73. Arch. dép. d'Ille-et-Vilaine, C 1, lettre de Jan de La Hamelinaye à l'intendant, Montauban, janvier 1782.

74. Arch. dép. d'Ille-et-Vilaine, C 1436, état du mouvement de la population de la subdélégation de Douarnenez en 1787. Cf. aussi Arch. dép. du Finistère, 2E 1503, cité dans GROUSSARD, David, La gestion de l'eau dans les villes bretonnes aux XVII et XVIII siècles, Thèse d'histoire, Université de Rennes 2, 2010, p. 492, 572. 
acte de la perte de nombreuses prérogatives, son successeur, Jean-Baptiste Pontcarré de Viarmes, réduit à 63 puis 64 le nombre de subdélégations. Pérennes, leurs territoires sont organisés par la pratique des subdélégués avec un chef-lieu, des centres secondaires et un réseau de correspondants. Malgré une construction progressive, les Bretons s'approprient le nouveau maillage territorial. Ainsi, lorsque Gaspard Louis Caze de La Bove propose de le rationaliser, il se heurte à la résistance des subdélégués et de certains habitants. Même si son successeur tient compte de sa réflexion, le projet n'aboutit pas et le territoire des subdélégations résiste, au moins jusqu'en 1790. À cette date, les révolutionnaires dissolvent les 704 subdélégations françaises, dont 65 en Bretagne. Ils les remplacent par un découpage complètement différent : celui des cantons et des départements ${ }^{75}$. En effet, malgré la thèse d'A. de Tocqueville, la continuité du territoire administratif n'est pas évidente ${ }^{76}$. Les subdélégations ne semblent pas avoir laissé beaucoup de marques sur les territoires d'aujourd'hui.

75. OzOUF-MARIGNIER, Marie-Vic, La formation des départements : la représentation du territoire français à la fin du XVIII siècle, Paris, EHESS, 1989, p. 364 et LAGADEC, Yann, "La formation des cantons en Bretagne : une représentation des territoires (1790-an IX) ", dans Lagadec, Yann, Le BiHAN, Jean et TANGUY, Jean-François, Le canton un territoire du quotidien?, Rennes, PUR, 2009, p. 23-35.

76. ToCQueville, Alexis de, L'Ancien Régime et la Révolution, 1856. 

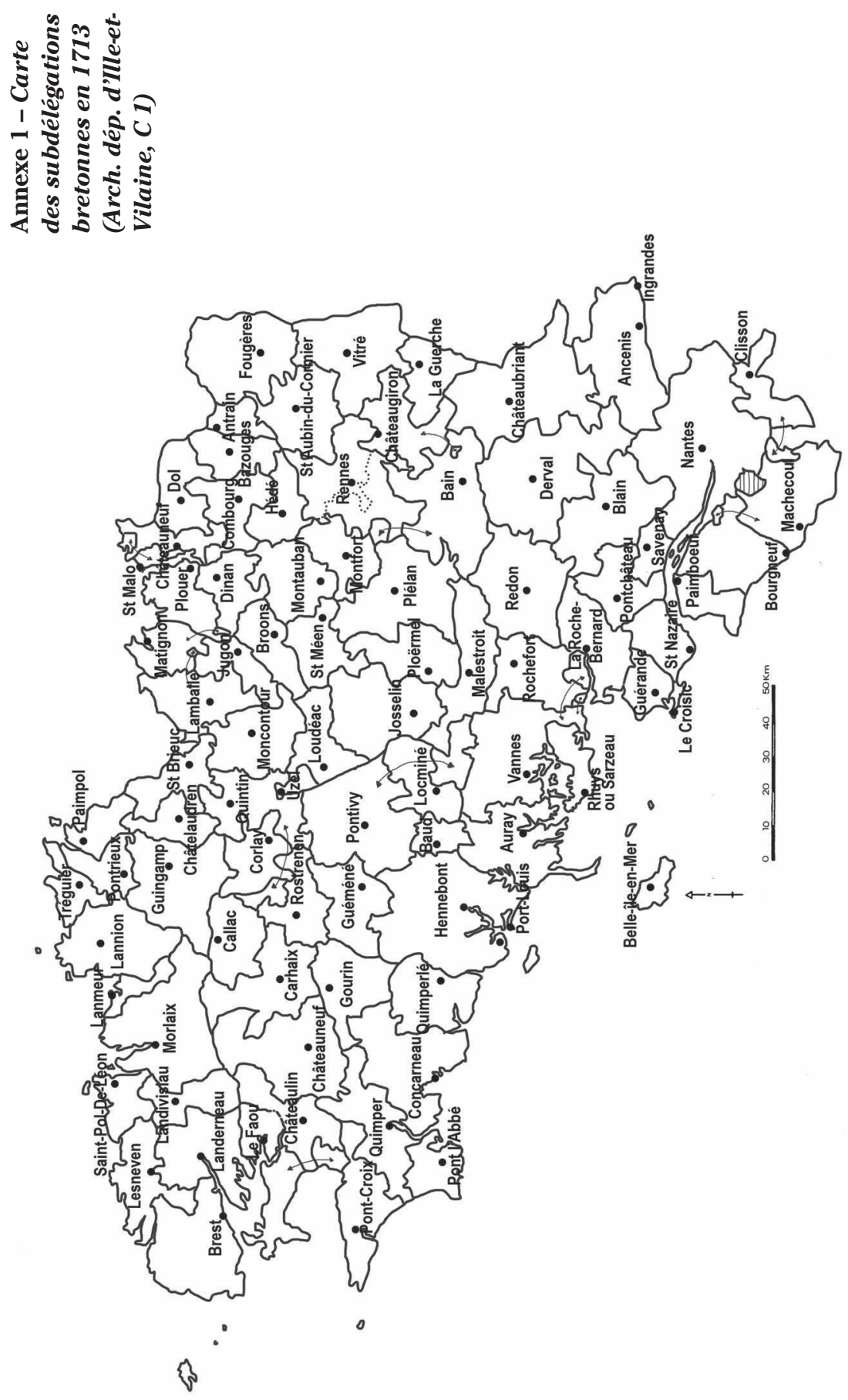

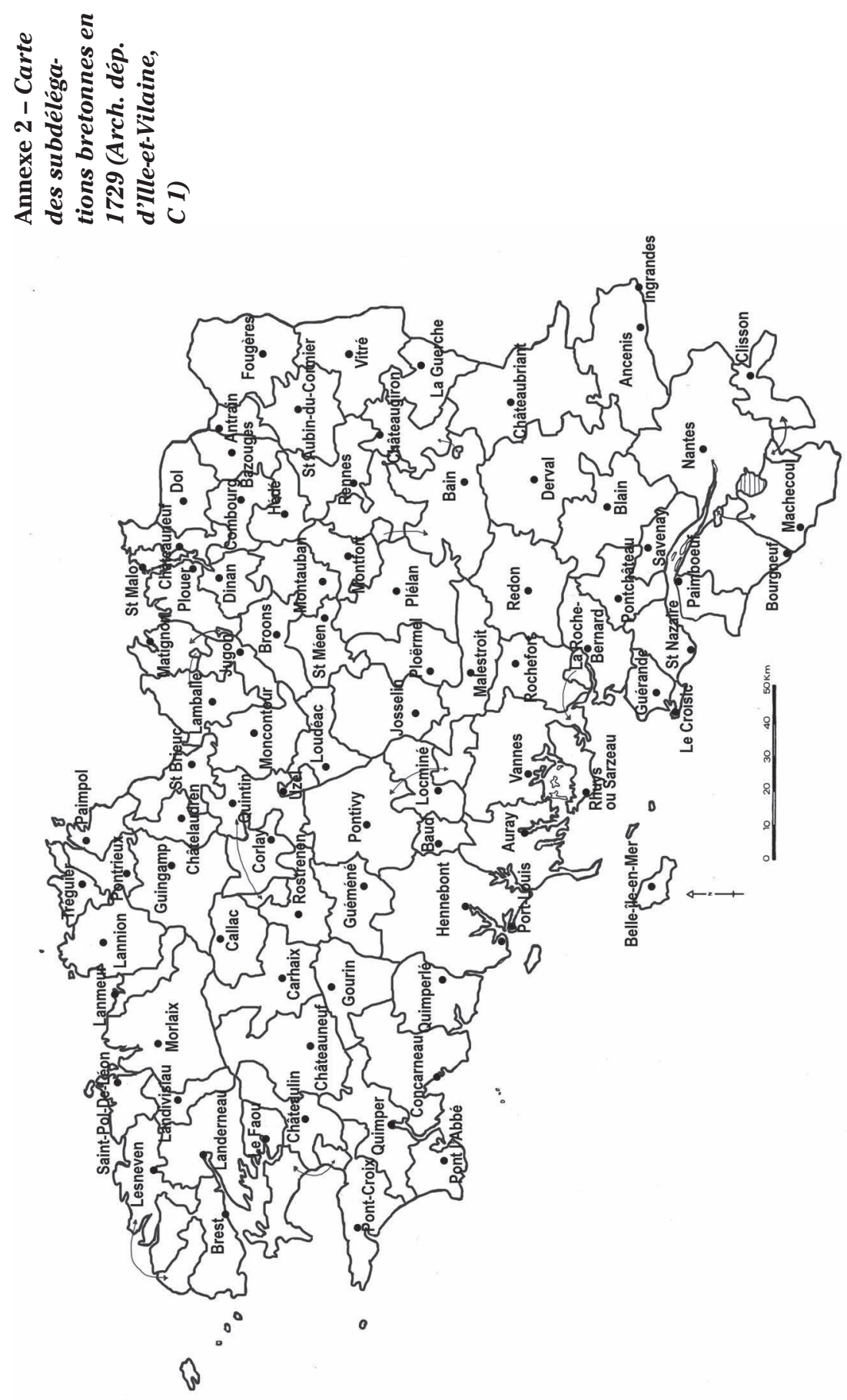

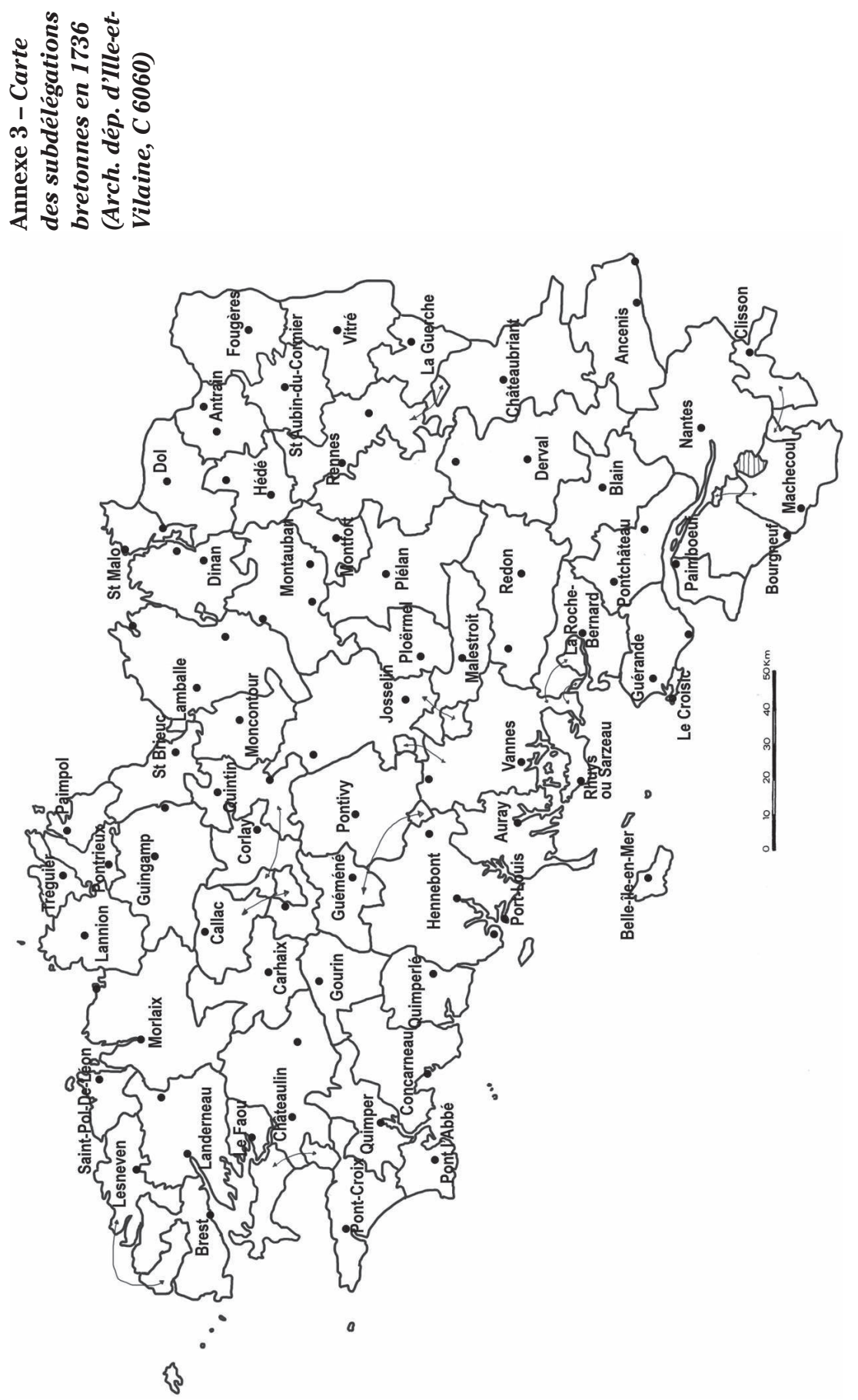

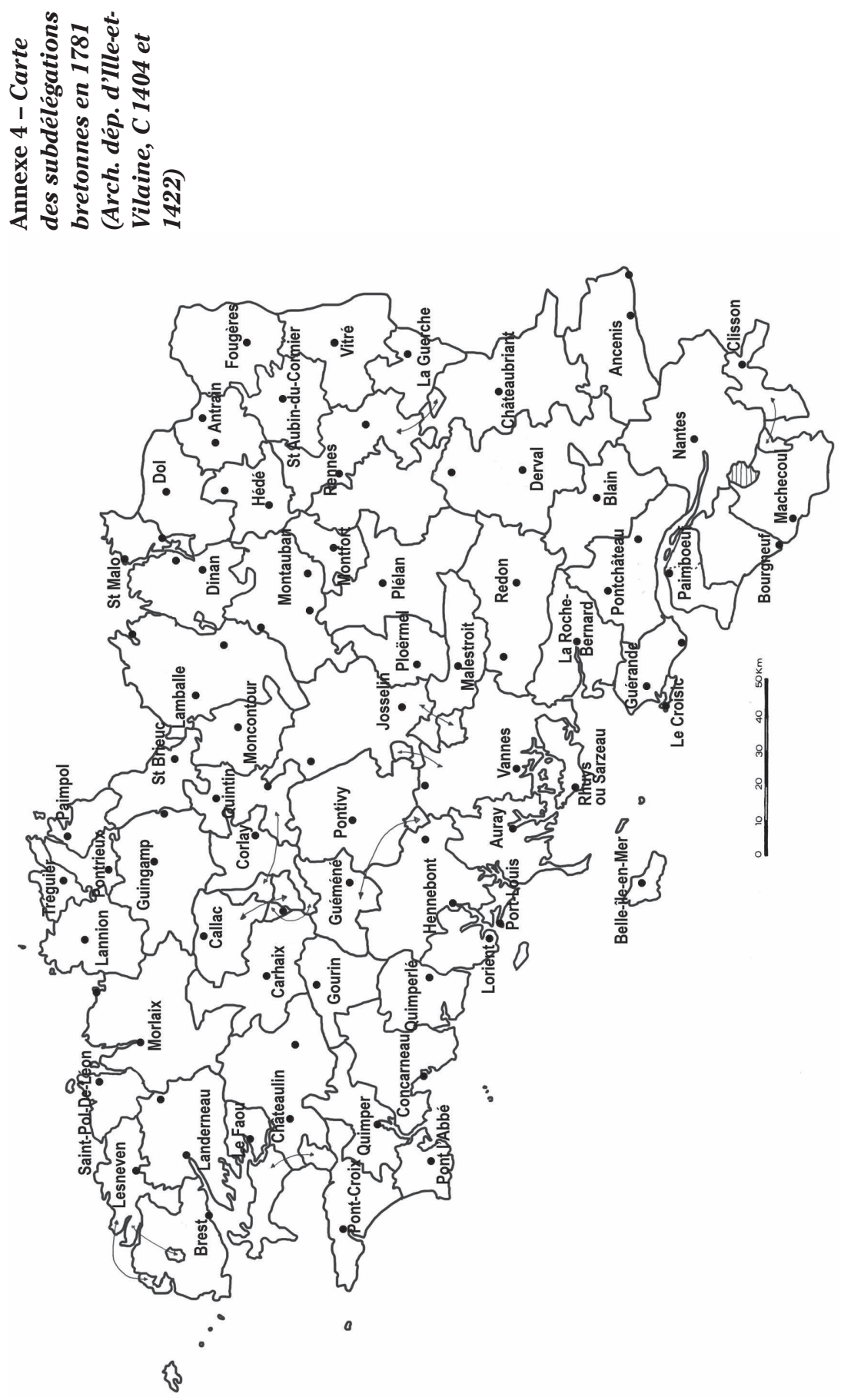


\section{RÉSUMÉ}

Entre 1689 et 1790, l'intendance de Bretagne se divise en une multitude de circonscriptions. Elles sont d'abord organisées en un vaste réseau de chefslieux centralisés par l'intendant. Puis, en 1729, ce dernier fixe leur ressort pour créer un véritable maillage administratif. Menée par les intendants successifs, cette construction territoriale tient compte des stratégies administratives provinciales, mais aussi de l'organisation pratique des subdélégués et de la concurrence des autres pouvoirs locaux. Les territoires ainsi créés sont complètement neufs. Leurs formes orientent le recrutement et le travail des subdélégués. Elles s'imposent finalement et deviennent de plus en plus difficiles à remodeler en dépit des projets de réduction des derniers intendants. L'étude de la construction des subdélégations bretonnes révèle bien les enjeux de la formation de circonscriptions et montre à quel point les usages administratifs de l'espace provincial peuvent créer de solides territoires.

\section{ABSTRACT}

Between 1689 and 1790, the intendants of Brittany divided their territory in subdelegations. They first delegated their tasks to a network of subdelegates located in the main towns. Gradually, subdelegates became the heads of new administrative districts that took into account both strategic aims and practical necessity as well as local rivalries. The limits of these subdelegations were officially established in 1729 with the participation of the subdelegates. In 1736, these administrative boundaries were modified because of the Provincial Assembly. Though at first they remained adjustable, these new territories later became fixed. Their shape influenced the work of the subdelegates. They became increasingly difficult to change, despite the efforts of the intendants. The study of the creation of the subdelegations underlines the strategic issues at stake and emphasises how administrative practices could create lasting territorial boundaries. 